\title{
Análise da declividade da malha cicloviária projetada para Londrina/PR utilizando técnicas de geoprocessamento
}

\section{Geoprocessing and slope analysis of the cycling network of Londrina/PR}

\section{Análisis de la pendiente de la red ciclista diseñada para Londrina / PR mediante técnicas de geoprocesamiento}

\author{
Matheus Oliveira Martins da Silva ${ }^{1}$ https://orcid.org/0000-0001-9023-158X \\ Victor Hugo Martinez 2 https://orcid.org/0000-0003-3245-4835 \\ Marciel Lohmann ${ }^{3}$ http://orcid.org/0000-0001-9243-5412
}

\footnotetext{
1 Programa de Pós Graduação em Geografia da Universidade Estadual de Londrina, Paraná, Brasil, oliveiramartins.matheus@gmail.com

${ }^{2}$ Universidade Estadual de Londrina-UEL, Londrina, Paraná, Brasil, victormartinez.vhm@gmail.com

${ }^{3}$ Departamento de Geociências/Programa de Pós Graduação em Geografia da Universidade Estadual de Londrina, Paraná, Brasil, marciel@uel.br
}

Recebido em: 12/01/2021

Aceito para publicação em: 21/03/2021

\section{Resumo}

O Programa Bicicleta Brasil, do extinto Ministério das Cidades - Secretaria Nacional de Transporte e da Mobilidade Urbana (BRASIL, 2007) recomenda que inclinações superiores a 5\% sejam evitadas pelos ciclistas no deslocamento urbano por se tratar de um transporte movido a esforço físico. Sendo assim, o objetivo desta pesquisa é verificar as condições de declividade da malha cicloviária projetada pelo município de Londrina (IPPUL, 2006; 2013; 2019; 2020) utilizando a estratégia de geração de um Modelo Digital de Elevação (MDE) e operações altimétricas em um software de geoprocessamento aplicados à malha. De acordo com os resultados obtidos, concluiu-se que $40,6 \%$ da malha proposta contempla uma inclinação abaixo de $5 \%$.

Palavras-chave: Infraestrutura cicloviária. Declividade. Londrina.

\begin{abstract}
The Bicycle Brazil Program, from the extinct Ministry of Cities - National Secretariat of Transport and Urban Mobility (BRASIL, 2007) recommends that gradients higher than $5 \%$ should be avoided by cyclists in urban commuting, since it is a transport powered by physical effort. Therefore, the objective of this research is to verify the slope conditions of the project of the cycle network by the
\end{abstract}

Geopauta, Vitória da Conquista, ISSN: 2594-5033, V. 5, n.1, 2021, e8056

Este é um artigo de acesso aberto sob a licença Creative Commons da CC BY 
city of Londrina (IPPUL, 2006; 2013; 2019; 2020) applying spatial analysis to a Digital Elevation Model (DEM) and the vector file of the project of the cycling network in a geoprocessing software. According to the obtained results, $40,6 \%$ of the proposed network is suitable for cycling infrastructure.

Keywords: Cycling infrastructura. Slope analysis. Londrina

\section{Resumen}

El Programa Bicicleta Brasil, del extinto Ministerio de Ciudades - Secretaría Nacional de Transporte y Movilidad Urbana (BRASIL, 2007), recomienda que los ciclistas eviten inclinaciones superiores al $5 \%$ en los desplazamientos urbanos por tratarse de un transporte impulsado por el esfuerzo físico. Por tanto, el objetivo de esta investigación es verificar las condiciones de deterioro de la red ciclista proyectada por la ciudad de Londrina (IPPUL, 2006; 2013; 2019; 2020) utilizando la estrategia de generación de un Modelo Digital de Elevación (DEM) y altimetría de operaciones. en software de geoprocesamiento aplicado a la malla. De acuerdo con los resultados obtenidos, se concluyó que el $40,6 \%$ de la cuadrícula propuesta presenta una pendiente menor al 5\%.

Palabras clave: Infraestrutura de bicicleta. Declínio. Londrina

\section{Introdução}

A precária mobilidade urbana, mais carros na rua e consequentemente o aumento de acidentes tornou-se um desafio para os gestores municipais. Desde 2001 com a aprovação do Estatuto da Cidade (Lei Federal 10.257/2001), a elaboração de planos de transporte incorporou-se à existência dos Planos de Mobilidade Urbana como instrumento de desenvolvimento urbano. Após 11 anos da existência do Estatuto da cidade é aprovada a Política Nacional de Mobilidade Urbana por meio da Lei Federal 12.587/2012 que estabelece prazos aos municípios, e tem como uma das suas diretrizes a "prioridade dos modos de transporte não motorizados sobre os motorizados" para oferecer o mínimo de segurança nos deslocamentos urbanos (MARTINS DA SILVA; CUNHA, 2020, p. 253-254).

Em 2004, é lançado pelo Governo Federal o Programa Brasileiro de Mobilidade por Bicicleta, também conhecido por "Bicicleta Brasil", um programa direcionado exclusivamente aos deslocamentos por bicicleta. Em 2007, integrando programa, é lançado o “Caderno de Referência para elaboração de Plano de Mobilidade por Bicicleta 
nas Cidades" que fornece subsídios para os municípios na implantação de um plano cicloviário, sendo também um importante instrumento na formulação de políticas de mobilidade urbana considerando a participação ativa das mais diversas esferas e principalmente os usuários de bicicletas (BRASIL, 2007).

Mapa 1- Rede cicloviária proposta e existente em Londrina/PR

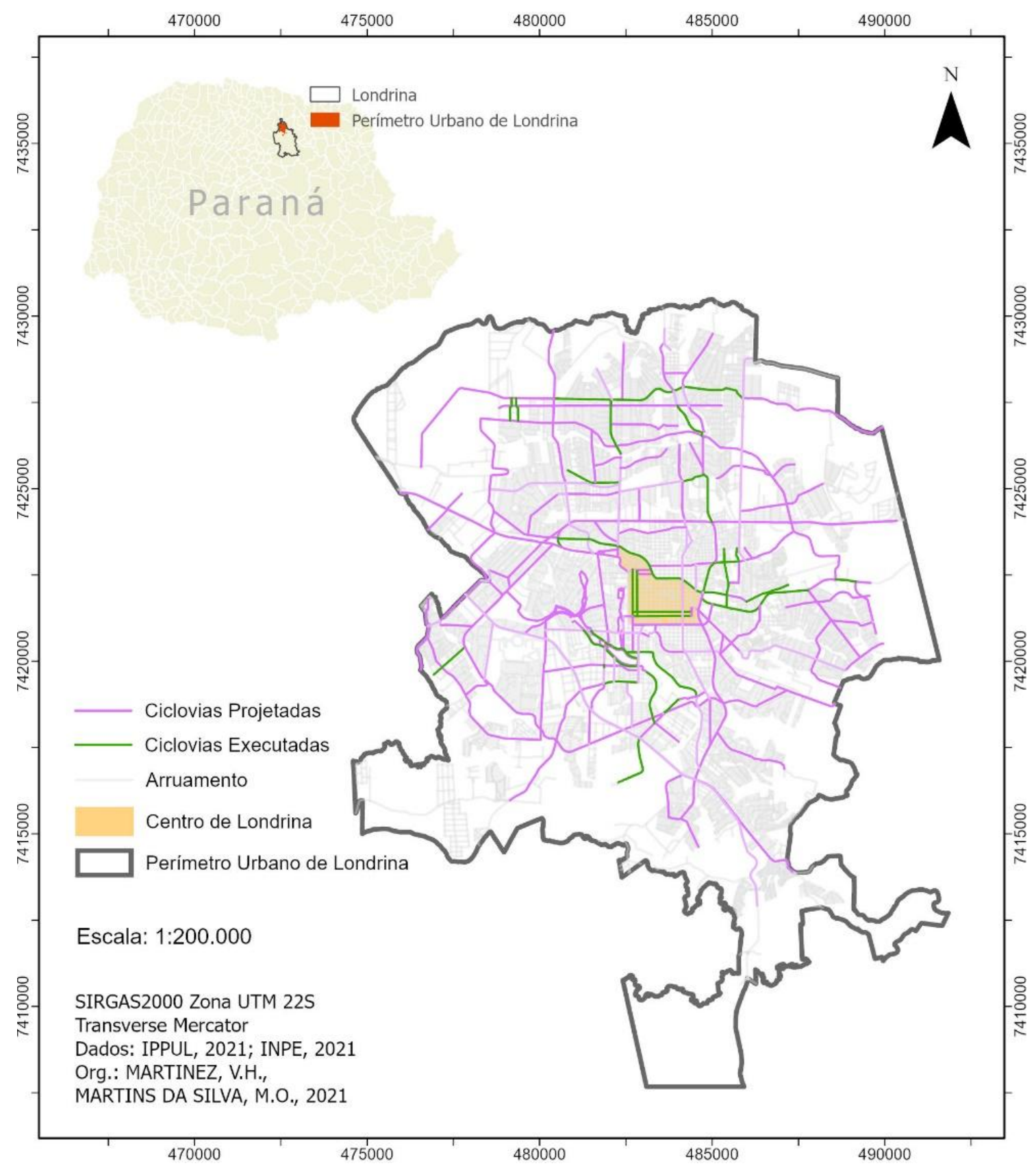

Fonte: MARTINEZ, V. H.; MARTINS DA SILVA, M. O., (2021)

Em 4 de outubro de 2018 é sancionada a Lei Federal 13.724 que institui o Programa Bicicleta Brasil (PBB) para incentivar o uso da bicicleta visando à melhoria 
das condições de mobilidade urbana. O PPB tem entre seus objetivos "aumentar a construção de ciclovias e a marcação de ciclofaixas e faixas compartilhadas (temporárias) nas pistas de rolagem" (BRASIL, 2018, p. 3, col. 2).

O recorte espacial da pesquisa (mapa 1) se dá na cidade de Londrina, no norte do Paraná, conta com uma área territorial de $1.652,569$ km² e uma população estimada de 575.377 habitantes, tendo uma densidade demográfica de $306,52 \mathrm{hab} / \mathrm{km}^{2}$ e constitui uma região metropolitana (IBGE, 2021).

Em 2006, o Instituto de Pesquisa e Planejamento Urbano de Londrina (IPPUL) planejou $60 \mathrm{~km}$ de ciclovias e ciclofaixas e o projeto inicial sofreu diversas alterações, sendo que até o ano de 2012 a cidade contava com apenas $12 \mathrm{~km}$ de vias para ciclistas. Em 2013, foram realizadas novas pesquisas e observou-se uma predominância no transporte por bicicleta para fins de estudos e trabalho (59\%) e com isso planejou-se 328,7 km, sendo que a execução atingiu $38 \mathrm{~km}$ em 2017 e cerca de $42 \mathrm{~km}$ em 2020 (MARTINS DA SILVA; CUNHA, 2020, p. 258).

Nas mais diversas cidades, o percurso do ciclista é diretamente afetado por ondulações do terreno e culturalmente a topografia acidentada desestimula o uso da bicicleta. Porém, a configuração topográfica não pode determinar a viabilidade para o ciclismo (BRASIL, 2007, p. 62). Sendo assim, defende-se que um bom planejamento cicloviário com base na compreensão das condições do terreno deve ser pilar para adotar ações estratégicas para facilitar o deslocamento do ciclista, principalmente no caso de Londrina, onde predominantemente a bicicleta é utilizada para o trabalho e estudos.

\section{Materiais e Métodos}

A declividade aceitável para infraestrutura cicloviária é variável. Nos Estados Unidos a inclinação sugerida alcança 8\% em trechos até 90 m (EUA, 1999), na Escócia são estabelecidos valores entre 3 e 7\% (ESCÓCIA, 2011) e na Colômbia em trechos até 90 m recomenda-se uma inclinação até 10\% (COLÔMBIA, 2016). 
O Programa Bicicleta Brasil indica que a inclinação ideal da rede cicloviária para o ciclista deve ser de no máximo 5\% em trechos até $100 \mathrm{~m}$, visto que este tipo de deslocamento requer esforço físico (BRASIL, 2007 p. 62).

Mapa 2- Declividade e projeto da malha cicloviária de Londrina

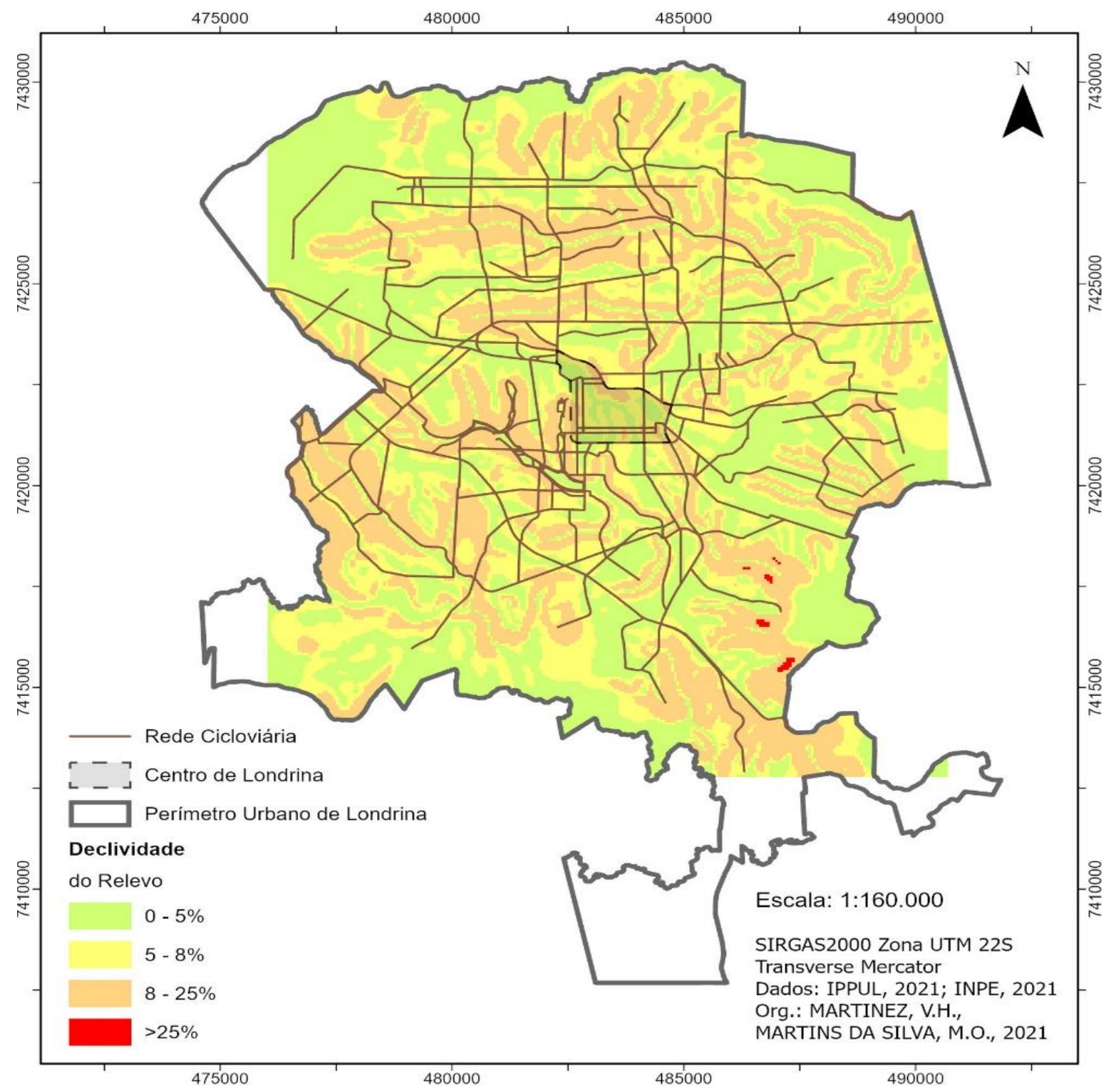

Fonte: MARTINEZ, V. H.; MARTINS DA SILVA, M. O., 2021

Com o objetivo de determinar a declividade do relevo e definir as parcelas indicadas ou não à prática ciclista, foi necessário gerar um Modelo Digital de Elevação (MDE) que "representa as altitudes da superfície topográfica agregada aos elementos geográficos existentes sobre ela, como cobertura vegetal e edificações" (IBGE, 2020, p. $1)$. 
O MDE foi gerado a partir do arquivo vetorial shapefile georreferenciado de curvas de nível de 1 x 1 metro da cidade de Londrina, disponibilizado pelo IPPUL. Este arquivo foi manipulado em ambiente SIG e com a utilização da ferramenta “TopoToRaster" foi gerado o MDE. De posse do MDE, utilizou-se a ferramenta "slope" para gerar a declividade da área de estudo (Fluxograma 1), sendo a mesma discretizada em quatro classes. Todo o processamento foi realizado no software ArcGIS Pro 2.7.0.

Fluxograma 1- Metodologia aplicada à pesquisa sobre malha cicloviária e declividade

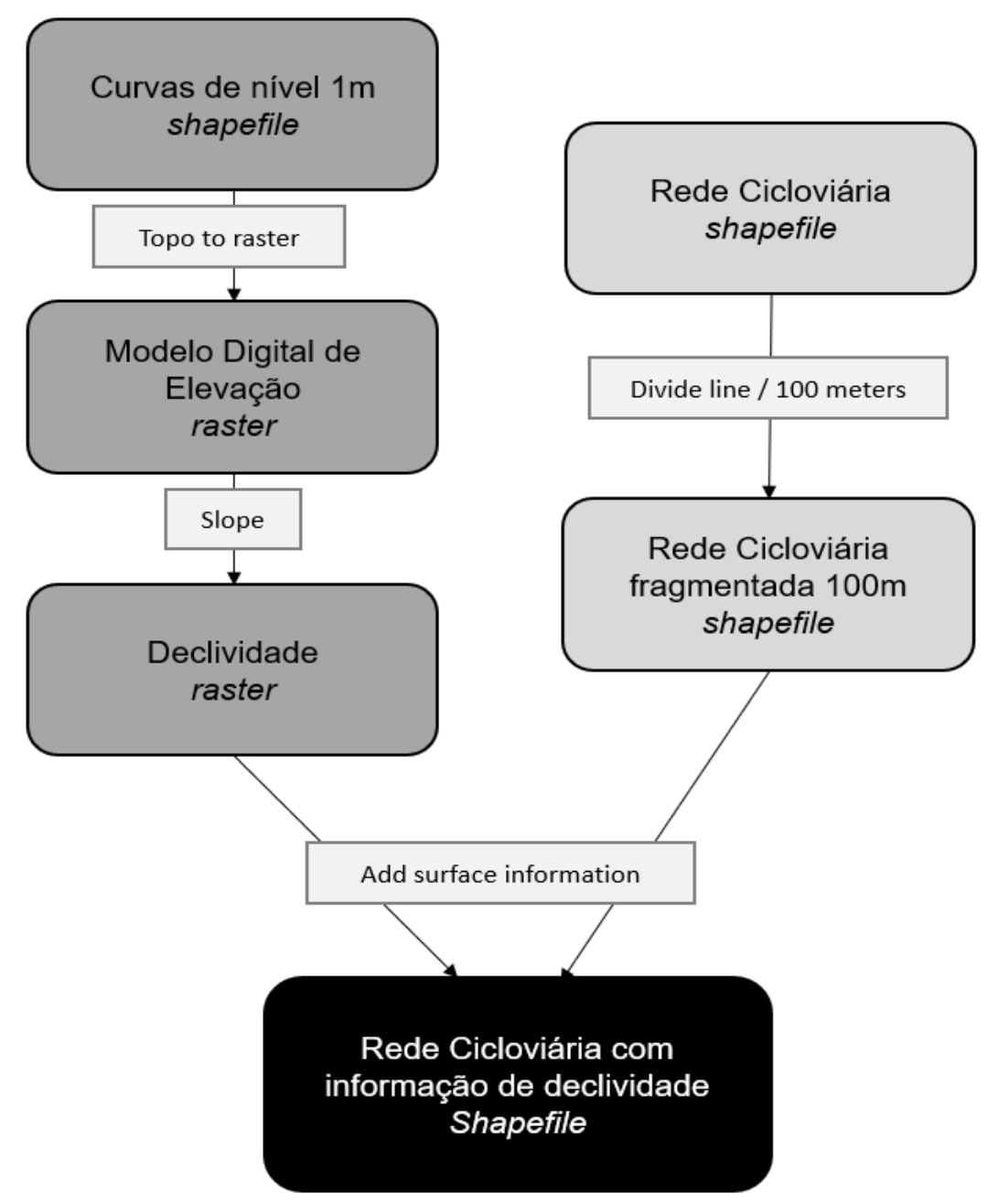

Fonte: Os autores, 2021

O arquivo da rede cicloviária de Londrina em formato vetorial shapefile foi também fornecido pelo IPPUL. Neste arquivo constam informações como a extensão de cada linha, sua localização e sua condição (implantada ou projetada). O mapa 2 representa o projeto da rede cicloviária de Londrina sobreposta à declividade do relevo.

Geopauta, Vitória da Conquista, ISSN: 2594-5033, V. 5, n.1, 2021, e8056 
Para acrescentar o valor de declividade a cada trecho da ciclovia, optou-se por fragmentá-la a cada 100 m, de acordo com metodologia adotada por Simeão; Manzato; Viviani (2018) que é baseada a partir da reflexão de metodologias que seguem padrões internacionais. Esta medida justifica-se, pois, a cada trecho da rede cicloviária será acrescido o valor médio dos pixels de declividade em que se sobrepõe. Quanto maior o trecho da linha, maior a quantidade de pixels e consequentemente maior a variável do valor de declividade. Com trechos menores, de 100m, este valor torna-se mais preciso, pois cada trecho sobrepõe-se de dois a três pixels. O fluxograma 1 representa a metodologia utilizada.

Com a realização das operações, as vias com inclinação abaixo de 5\% foram consideradas "aceitáveis" e acima de 5\% servirão de "pontos de alerta" para implantação de infraestrutura que auxilie o ciclista nos deslocamentos.

\section{Resultados e discussões}

Com o tratamento dos dados, os resultados entre 0 e $5 \%$ de declividade atingiram 40,6\%, o que representa uma média abaixo da recomendada por Brasil (2007), porém para entender essa complexidade, verificou-se por meio da tabela de atributos que os valores de 5 a 6\% determinam uma extensão de 13,5\% da malha, ou seja, 54,1\% da malha corresponde a uma inclinação de 0 a 6\% (Quadro 1).

Quadro 1- Extensão da malha cicloviária conforme a declividade baseada em 5\%

\begin{tabular}{|c|c|c|}
\hline Classe de declividade & Extensão $(\mathrm{km})$ & Extensão $(\%)$ \\
\hline $0-5 \%$ & 133,6 & 40,6 \\
\hline $5-6 \%$ & 44,4 & 13,5 \\
\hline $6-8 \%$ & 69,0 & 20,9 \\
\hline$>8 \%$ & 81,1 & 25 \\
\hline
\end{tabular}

Fonte: Os autores, 2021

A compreensão dos dados apresentados se dá na espacialização representada no mapa 3. Como são muitos trechos de $100 \mathrm{~m}$, é inviável a visualização cartográfica do 
valor de declividade de cada trecho, sendo assim, são apresentadas as variações gerais de $0,3 \%$ a $5 \%$ e $5,1 \%$ a $19,7 \%$. Os dados de cada via estão disponíveis na tabela de atributos gerada e que podem subsidiar trabalhos futuros e também a tomada de decisão dos gestores, não sendo aplicável a sua apresentação conforme o objetivo central deste trabalho.

Mapa 3 - Trechos da malha cicloviária de Londrina com declividade aceitável (até 5\%) e com pontos de alerta

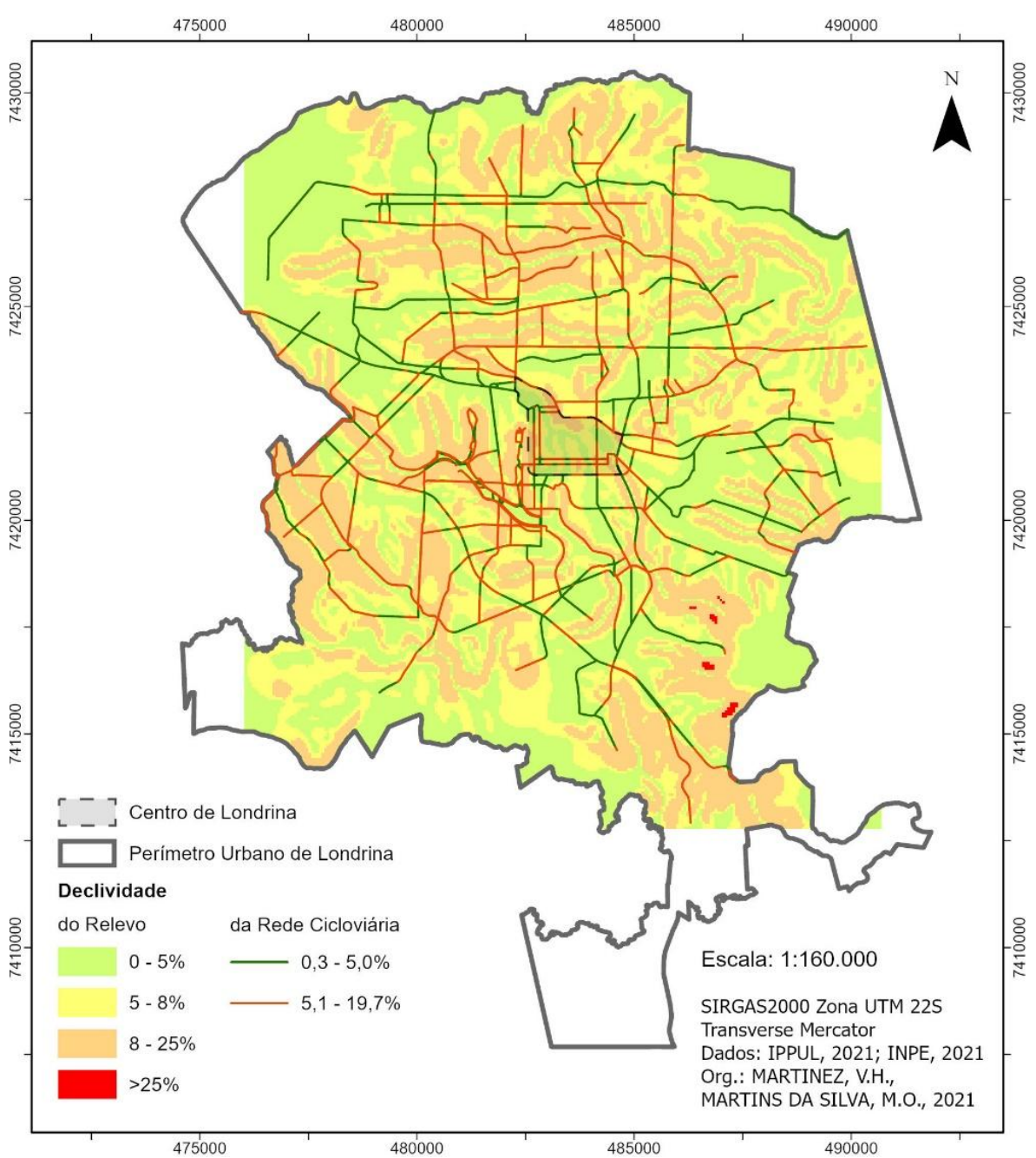

Fonte: MARTINEZ, V. H.; MARTINS DA SILVA, M. O., 2021

Apesar de 40,6\% da rede contemplar a declividade inferior a 5\%, muitos dos trechos caracterizados oscilam entre 5,1 a 5,5\% o que ainda é aceitável, pois podem existir distorções mínimas nos resultados do processamento, pode existir variações no comprimento dos trechos e também considera-se outras bibliografias mundiais onde a 
declividade até 8\% (Quadro 2) é aceitável dependendo do terreno e das condições ofertadas ao ciclista (EUA, 1999; COLOMBIA, 2016; ESCÓCIA, 2011).

Quadro 2- Extensão da malha cicloviária conorme a declividade baseada em 8\%

\begin{tabular}{|c|c|c|}
\hline Classe de declividade & Extensão $(\mathrm{km})$ & Extensão $(\%)$ \\
\hline $0-5 \%$ & 133,6 & 40,6 \\
\hline $5-8 \%$ & 113,5 & 34,4 \\
\hline$>8 \%$ & 81,1 & 25 \\
\hline
\end{tabular}

Fonte: Os autores, 2021

A compreensão dos dados apresentados se dá na espacialização representada no mapa 4 , com variações de $0,3 \%$ a $8 \%$ e de $8,1 \%$ a $19,7 \%$ :

Mapa 4. Trechos da malha cicloviária de Londrina com declividade até $8 \%$

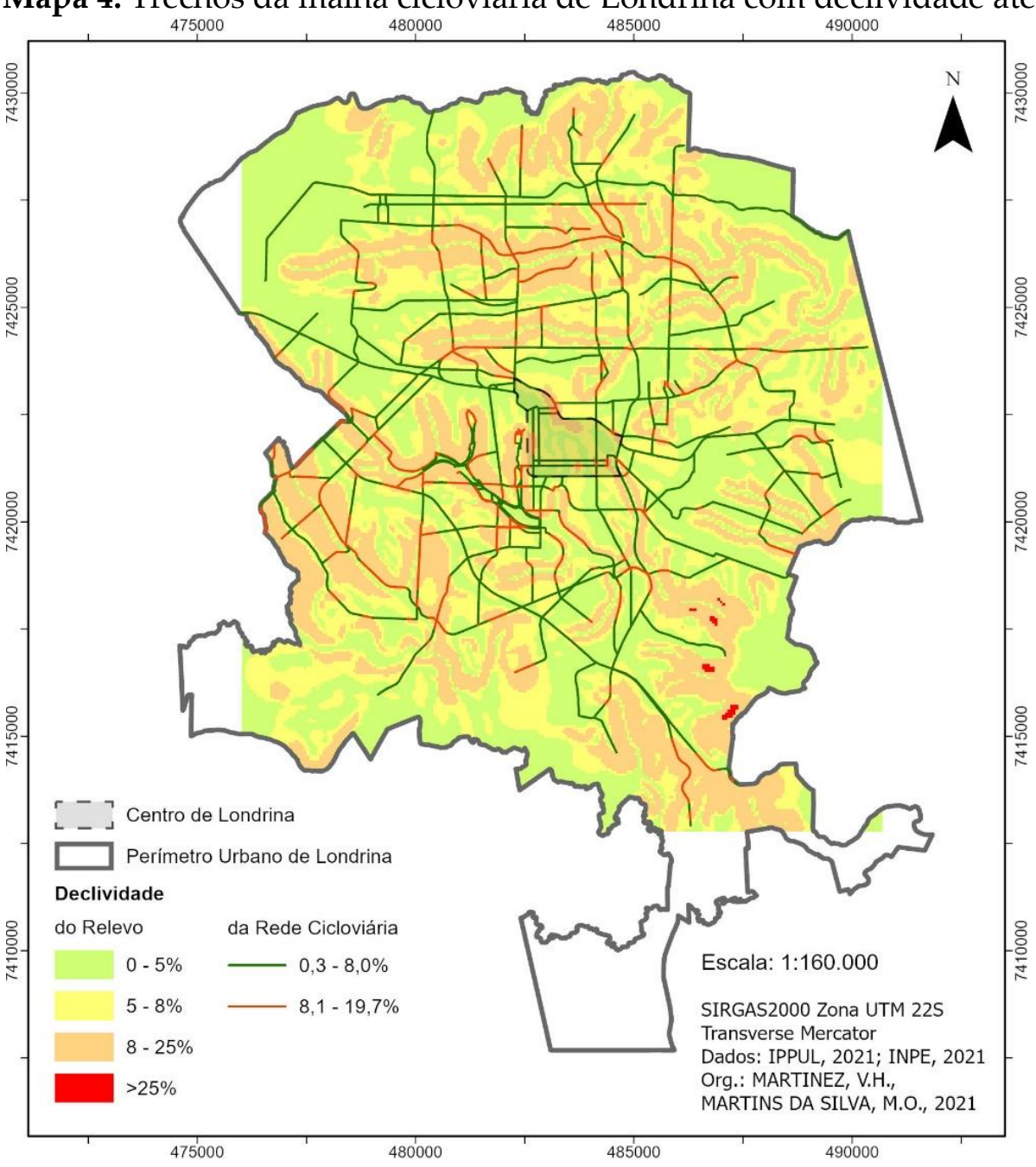

Fonte: MARTINEZ, V.H.; MARTINS DA SILVA, M.O., 2021

Geopauta, Vitória da Conquista, ISSN: 2594-5033, V. 5, n.1, 2021, e8056 
Neste caso, 75\% da rede contempla os padrões mundiais. Para suprir a demanda do ciclista nas regiões que exijam maior esforço físico e são consideradas pontos de alerta conforme a metodologia utilizada, o PBB recomenda:

Art. 5o [...] I - o estímulo ao desenvolvimento de projetos de infraestrutura cicloviária; II - a implantação de ciclovias, ciclofaixas, faixas compartilhadas, devidamente sinalizadas; III - a construção de bicicletários em terminais do sistema de transporte público coletivo; IV a instalação de paraciclos ao longo das vias de circulação e de estacionamentos específicos nos locais de grande fluxo de pessoas; V - a instalação de equipamentos de apoio aos usuários, como banheiros públicos e bebedouros, em locais estratégicos; VI - a implantação de sistema de locação de bicicletas a baixo custo nos terminais do sistema de transporte público coletivo, em centros comerciais e em outros locais de grande fluxo de pessoas; VII - a elaboração e divulgação de campanhas educativas relacionadas ao uso seguro da bicicleta e seus benefícios. (BRASIL, 2018, p. 3, col. 2).

É comum o argumento de que a declividade é um fator determinante para a utilização da bicicleta enquanto meio de transporte. Entende-se que apesar da rede cicloviária de Londrina apresentar trechos que prejudiquem o ciclista, a maior parte da proposta contempla os requisitos mínimos para a implantação de infraestrutura adequada que dê suporte e segurança.

É necessário considerar o avanço tecnológico e o aperfeiçoamento das bicicletas por meio do sistema de marchas. Diante disso, apenas a configuração topográfica não pode determinar a viabilidade para o ciclismo. É necessário seguir a tendência natural do sistema viário em direções que suavizem a declividade da rampa e possibilitarão a promoção do uso de bicicleta enquanto meio de transporte (BRASIL, 2007, p. 62).

\section{Considerações finais}

O objetivo da pesquisa foi atingido com êxito e serve como subsídio para os gestores públicos na tomada de decisão. A metodologia utilizada precisa dialogar também com os ciclistas que participam in loco dos desafios ao pedalar na cidade, pois a percepção é variável e não depende apenas dos modelos matemáticos utilizados. 
Defende-se a expansão da rede cicloviária como elemento de promoção da mobilidade ativa e consequentemente a sua manutenção e oferta de serviços de apoio como prevê o PBB. Os dados apresentam uma variação baixa e que se aproxima muito dos 5\% aceitos pelo Caderno de Referência para elaboração de Plano de Mobilidade por Bicicleta nas Cidades, o que defende a tese de que Londrina é uma cidade ciclável caso convirja com as demais recomendações técnicas.

\section{Referências}

BRASIL. Decreto-lei $n^{\circ}$ 10.275. Estatuto da cidade, de 10 de julho de 2001. Regulamenta os artigos. 182 e 183 da Constituição Federal, estabelece diretrizes gerais da política urbana e dá outras providências. Diário Oficial da República Federativa do Brasil, Brasília, 11 jul., 2001.

BRASIL. Ministério das Cidades. Programa Brasileiro de Mobilidade por Bicicleta Bicicleta Brasil. Caderno de Referência para elaboração de Plano de Mobilidade por Bicicleta nas Cidades. Brasília, 2007.

BRASIL. Decreto-lei ${ }^{\circ} 12587$, de 3 de janeiro de 2012. Institui as diretrizes da Política Nacional de Mobilidade Urbana. Diário Oficial da República Federativa do Brasil, Brasília, 3 jan 2012.

BRASIL. Decreto-lei n 13724, de 4 de outubro de 2018. Institui o Programa Bicicleta Brasil (PBB) para incentivar o uso da bicicleta visando à melhoria das condições de mobilidade urbana. Diário Oficial da República Federativa do Brasil, Brasília, 4 out., 2018.

COLOMBIA. Guía de ciclo-infraestructura para ciudades colombianas. Bogotá D.C., Ministerio de Transporte de Colombia, 2016.

ESCÓCIA. Cycling by design 2010. Glasgow, Transport Scotland, 2011.

ESTADOS UNIDOS DA AMÉRICA. Guide for the development of bicycle facilities. Washington D.C., American Association of State Highway and Transportation Officials - AASHTO, 1999.

IBGE. Instituto Brasileiro de Geografia e Estatística. Cidades e Estados. Disponível em: $<$ https://www.ibge.gov.br/cidades-e-estados/pr/londrina.html> Acesso em 11 jan. 2021. 
IBGE. Instituto Brasileiro de Geografia e Estatística. Modelo Digital de Elevação MDE. Disponível em: <https://www.ibge.gov.br/geociencias/modelos-digitais-desuperficie/modelos-digitais-de-superficie/10856-mde-modelo-digital-deelevacao.html?=\&t=o-que-e $>$ Acesso em 11 jan. 2021.

IPPUL. Instituto de Pesquisa e Planejamento Urbano de Londrina. Rede Cicloviária de Londrina. Disponível em: $<$ http://ippul.londrina.pr.gov.br/index.php/rede-cicloviariade-londrina.html> Acesso em 11 dez. 2020.

MARTINS DA SILVA, M. O. ; CUNHA, F. C. A. Rede cicloviária e acidentes envolvendo ciclistas em Londrina/PR. Caminhos de Geografia. Uberlândia, v. 21, n.73, p. 253-268, março, 2020.

SIMEÃO, J. V. P. ; MANZATO, G. G. ; VIVIANI, E. Recursos de geoprocessamento aplicados à análise da declividade da malha cicloviária da cidade de São Paulo. Revista Brasileira de Cartografia, vol. 71, n.1: Uberlândia, janeiro/março, 2019.

Contribuição dos autores:

Matheus Oliveira Martins da Silva: Elaboração, Coleta e interpretação dos dados, Mapeamento, discussão dos resultados, pesquisa bibliográfica

Victor Hugo Martinez:, Coleta e interpretação dos dados discussão dos resultados, Mapeamento, pesquisa bibliográfica Marciel Lohmann: Interpretação dos dados; supervisão e revisão do texto. 